\title{
A NEW METHOD FOR DETERMINING AIR PERMEABILITIES OF WOOD-BASED PANELS
}

\author{
Takashi Tanaka ${ }^{1, \$}$ \\ https://orcid.org/0000-0002-7074-7703
}

\begin{abstract}
In this study, a new apparatus for measuring the air permeability of wood-based panel specimens without using water displacement was developed with the aim of decreasing the influence of variation in atmospheric pressure on permeability measurement. Validation experiments were conducted using plywood, oriented strand board (OSB), particleboard, and medium-density fiberboard (MDF) panels and a control specimen sealed with an epoxy resin. The background (leakage) flow of the apparatus was evaluated based on the experimental results of the control specimen. A methodology for the determination of air permeability based on Darcy's law for gases and the evaluated background flow rate was proposed. The results of the current study were compared with those obtained in a previous study, indicating that the new method provides valid measurements for woodbased panels with high and low air permeability. No significant influence of variation in atmospheric pressure on the experimental results was observed, suggesting that the proposed method is suitable for a long-term continuous experiment for evaluating a specimen with extremely low permeability.
\end{abstract}

Keywords: Air permeability, Darcy's law, medium density fiberboard, Oriented strand board, particleboard, plywood, pressure measurement.

\section{INTRODUCTION}

Several methods for measuring the air permeability of wood have been developed (Resch and Echlund 1964, Choong and Fogg 1968, Petty and Puritch 1970, Perré 1987, Siau 1995, Perré 2007, Ai et al. 2017). Using these methods and similar methods, the air permeability of various wood species in various directions has been determined (Resch and Echlund 1964, Choong and Fogg 1968, Comstock 1970, Perré 1987, Matsumura et al. 1994, Fujii et al. 1997, Lihra et al. 2000, Rayirath and avramidis 2008, Tanaka et al. 2015, Poonia et al. 2016, Taghiyari and Avramidis 2019).

The Rising-Water Volume Displacement method, which has been introduced as a simple apparatus for student use by Siau (1995), is suitable for woods of high and low permeability. Because of its simplicity and versatility, the method is employed not only for wood but also for several wood-based panels (Tanaka 2014). During the experiments for woods of very low permeability using this method, however, a long-term experiment is necessary in order to decrease the difficulty in measuring a small increase in water level inside a transparent glass tube before and after water displacement. Here, according to the author's experience, variation in atmospheric pressure during the experiment is quite influential on the readings of the water level inside the glass tube.

In this study, a new apparatus without using water displacement for measuring air permeability was built from common lab instruments with the intention of decreasing the influence of variation in atmospheric pressure on permeability assessment. Validation experiments were conducted using several wood-based panels, and the methodology for the determination of air permeability based on the experimental data was proposed. 
The determined air permeability was compared with the results obtained in a previous study (Tanaka 2014) and the validity of the proposed method was verified. The influence of variation in atmospheric pressure on permeability assessment and suitability for a long-term continuous experiment for the evaluation of specimens with extremely low permeability was discussed.

\section{MATERIALS AND METHODS}

\section{Sample preparation}

Seven cylindrical wood-based panel specimens $21 \mathrm{~mm}$ in diameter (Table 1) were recalled from the previ-ous experiment (Tanaka 2014). All specimens were bonded with an acrylic tube $21 \mathrm{~mm}$ in diameter using an epoxy resin adhesive (Quick Set 30, Konishi Co. Ltd., Tokyo) (Figure 1) and had been stored in a climate room at $20{ }^{\circ} \mathrm{C}$ and $65 \%$ relative humidity. In the present study, an acrylic tube with a dead end with adhesive tape and epoxy resin was made as a control specimen (Figure 2).

Table 1: Testing panels.

\begin{tabular}{|c|c|c|c|c|}
\hline $\begin{array}{c}\text { Panel Specimen } \\
\text { Plywood A (Cryptomeria } \\
\text { japonica) }\end{array}$ & $\begin{array}{c}\text { Thickness } \\
(\mathrm{mm})\end{array}$ & $\begin{array}{c}\text { Diameter } \\
(\mathrm{mm})\end{array}$ & Ply & $\begin{array}{c}\text { Air Permeability } k \\
\left(10^{-12} \mathbf{m}^{3} / \mathrm{m} \mathrm{s} \mathrm{Pa}^{1}\right.\end{array}$ \\
\hline $\begin{array}{c}\text { Plywood B (Larix kaempferi) } \\
\text { Plywood C (Larix gmelinii) }\end{array}$ & 12,69 & 21 & 5 -ply & 0,76 \\
\hline OSB U (made in EU) & 9,6 & 21 & - & 0,88 \\
\hline OSB N (made in North America) & 11,34 & 21 & - & 67,9 \\
\hline Particleboard & 12,07 & 21 & - & 156 \\
\hline MDF & 12,08 & 21 & - & 23900 \\
\hline
\end{tabular}

${ }^{1}$ Tanaka 2014
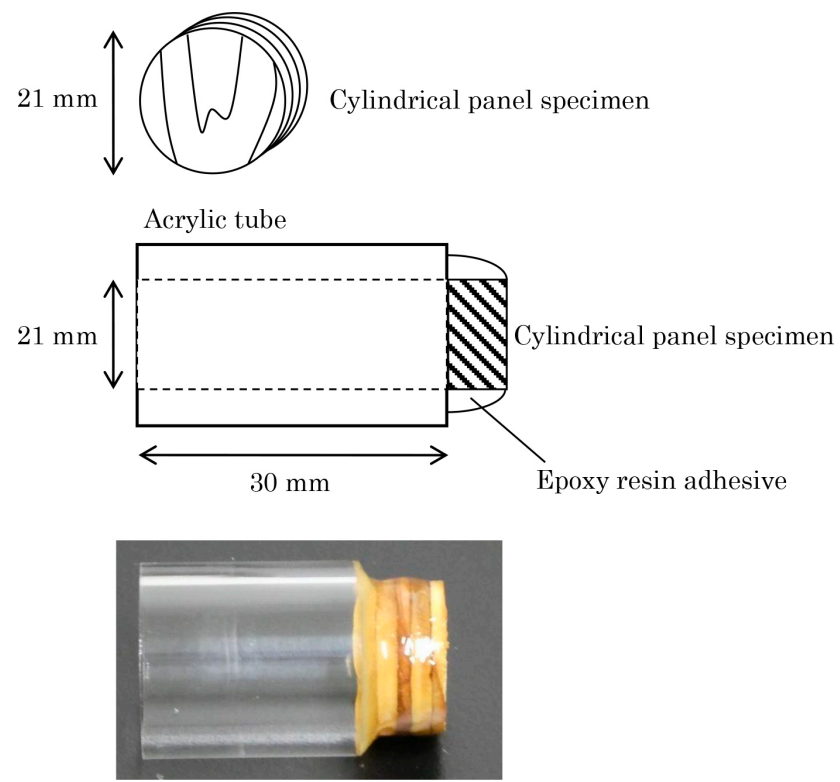

Figure 1: Schematic and photograph of the wood-based panel specimen. 

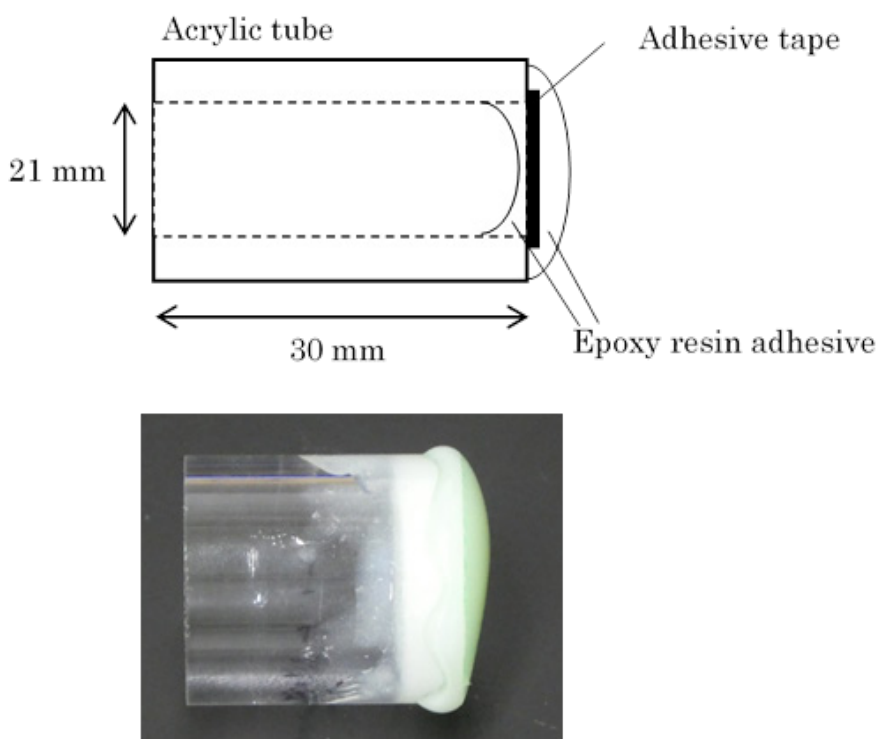

Figure 2: Schematic and photograph of the control specimen.

\section{Experimental}

A new air permeability measurement system was built with two absolute pressure meters (Testo 511), a diaphragm vacuum pump (KNF Japan, N86KN.18), a needle valve, and rubber vacuum hoses of 6-mm and 25 -mm internal diameter in a climate room at $20^{\circ} \mathrm{C}$ and $65 \%$ relative humidity (Figure 3 ). Each specimen was mounted to the end of the measurement system, and the vacuum pump was operated with the needle valve open. The valve was closed when the internal pressure of the system $(p)$ reached approximately $700 \mathrm{hPa}$. The internal pressure $(p)$, atmospheric pressure $\left(p_{\mathrm{a}}\right)$, and time $(t)$ were recorded every minute until $t$ reached 15 min. The experiment for the control specimen was repeated 20 times over four days (Day 1-4): five runs on each day. The panel specimens were tested on a day after two test runs using the control specimen. Here, the $t-p$ curves of the MDF and particleboard cannot be recorded because of the excessive permeability to air.

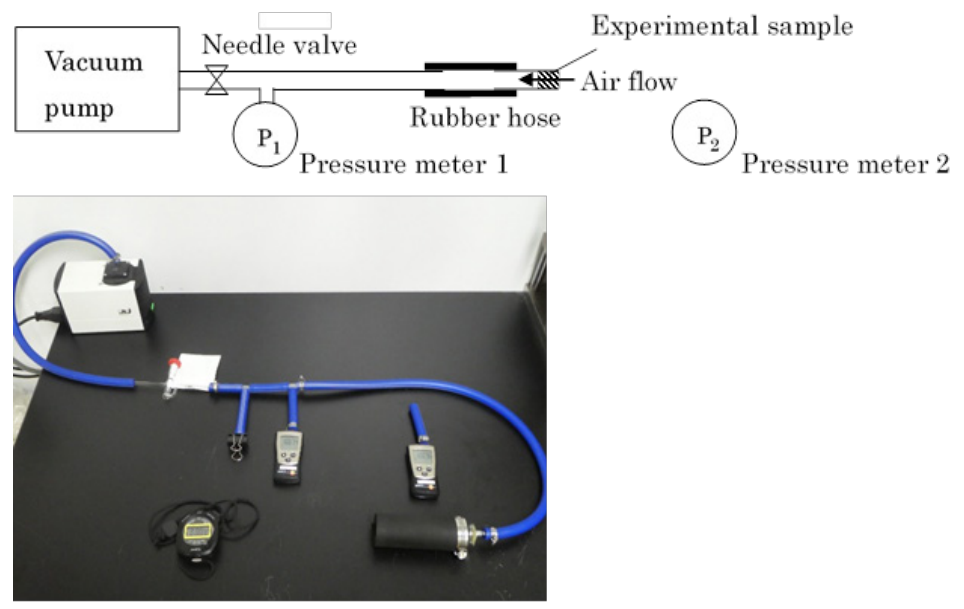

Figure 3: Schematic and photograph of the measurement system. 


\section{Additional experiments with surge tank}

For the measurements of highly permeable panels (OSB, particleboard, and MDF), an additional surge tank (a conical flask with a capacity of $3000 \mathrm{~mL}$ ) was installed between the needle valve and the internal pressure meter (Figure 4). All the panel specimens were tested on a day after two test runs using the control specimen.

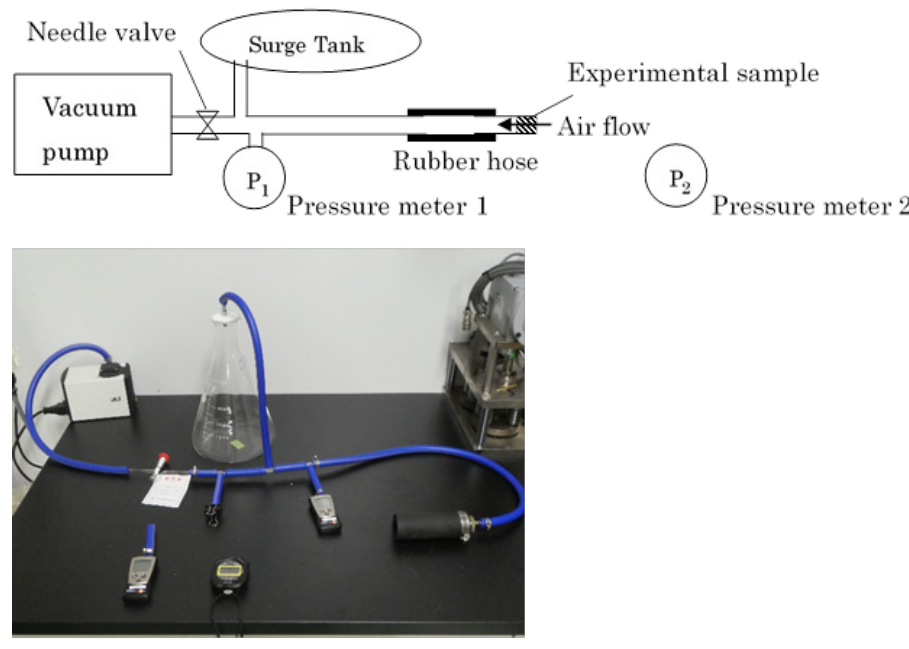

Figure 4: Schematic and photograph of the measurement system with a surge tank.

\section{Long-term experiment of control specimen}

The control specimen was placed on the apparatus without the surge tank. The vacuum pump was operated with the needle valve open. The needle valve was closed when the internal pressure reached approximately 700 $\mathrm{hPa}$. The internal and atmospheric pressures were recorded for $60 \mathrm{~h}$.

\section{RESULTS AND DISCUSSION}

\section{Control specimen experiment results}

Figure 5 shows the relationship between the internal pressure of the experimental system $(p)$ and time $(t)$ under the control specimen experiments on Day 1. The internal pressure of the system rapidly increased for the first few minutes of each run. Thereafter, the pressure increased, gradually decreased and became almost constant before $t=10 \mathrm{~min}$. Similar results were obtained on days 2-4. The results suggest that the pressure increase during the period from $t=10$ to $t=15(d)$ provides an indication of the leakage flow into the experimental system. Furthermore, the pressure increase in the first run on any day was significantly larger than that in the 2nd-5th runs (Figure 6). Although the reason behind this phenomenon is unclear, the result of the first run on each day should be rejected as unsuitable for evaluation. 


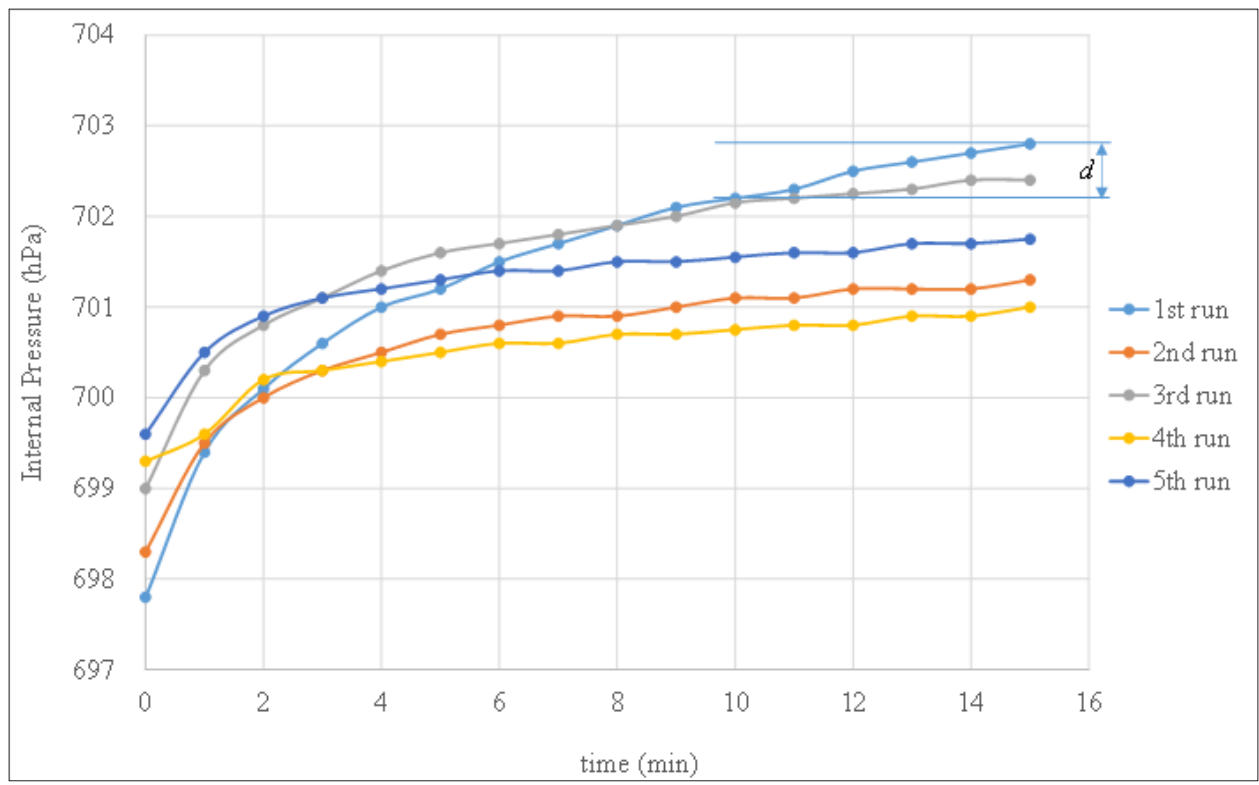

Figure 5: Relationship between time and the internal pressure of the system in the control specimen experiment (Day 1).

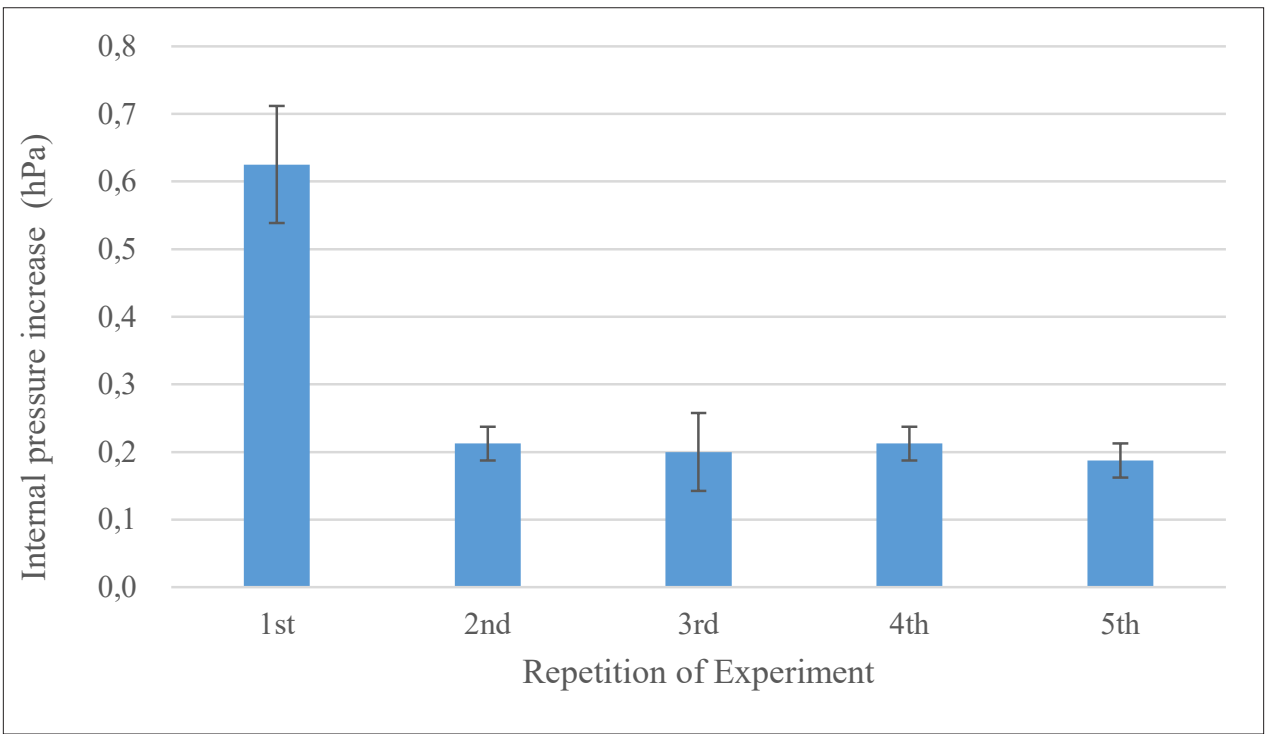

Figure 6: Influence of the repetition ( $\left(1^{\text {st }}-5\right.$ th runs) of the control specimen experiment on the internal pressure increase from $t=10$ to $t=15$.

\section{Evaluation of the leakage flow rate}

As mentioned above, the cause of the internal pressure increase of the experimental system during the control specimen measurement is considered as the leakage flow into the experimental system. Assuming that air is an ideal gas, the amount of air leaking into the system during the period from $t=10$ to $t=15(n)$ can be calculated using the following Equation 1: 


$$
(100 d) V_{i}=n R T
$$

Solving for $n$ in Equation 2,

$$
n=\frac{(100 d) V_{i}}{R T}
$$
tion 3:

The leakage volume of air under atmospheric pressure $V_{\mathrm{lk}}$ is determined by the following ideal gas Equa-

$$
\left(100 \overline{p_{a}}\right) V_{I k}=n R T
$$

Substituting Equation (2) into Equation (3) is Equation 4,

$$
V_{l k}=\frac{\frac{(100 d) V_{i}}{R T} R T}{\left(100 \overline{p_{a}}\right)}=\frac{d V_{i}}{\overline{p_{a}}}
$$

The leakage flow rate $Q_{\mathrm{lk}}$ is obtained by dividing $V_{\mathrm{lk}}$ by the period of time in Equation 5:

$$
Q_{l k}=\frac{V_{l k}}{(60 \Delta t)}=\frac{d V_{i}}{(60 \Delta t) \overline{p_{a}}}
$$

The leakage flow rate of each run was calculated using Equation (5). The average leakage flow rate from the 2 nd to the 5th runs over the four-day experiments and the standard deviation was successfully obtained Equation 6 and Equation 7:

$$
\begin{gathered}
\overline{Q_{l k}}=0,000000000063 \\
\sigma=0,000000000011
\end{gathered}
$$

\section{Determination of air permeability of testing panels}

From Equations (4) and (5), the volume of air flow into the system $V$ and the average flow rate $Q$ are determined by the following Equation 8 and Equation 9:

$$
V=\frac{d V_{i}}{\overline{p_{a}}}
$$




$$
Q=\frac{d V_{i}}{(60 \Delta t) \overline{p_{a}}}
$$

Figure 7 shows the relationship between the time and internal pressure of the system during the panel specimen experiments. These increases in the internal pressure shown in Figure 7 resulted from both the air flow through the panel specimen and from the leakage of the system. Assuming the leakage flow rate is constant regardless of the specimen material, the air flow rate through the panel during the period of time from $t=10$ to $t=15\left(Q_{\text {panel }}\right)$ can be evaluated by subtracting the average leakage flow rate from the total flow rate during the period of time from $t=10$ to $t=15$, Equation 10:

$$
Q_{\text {panel }}=Q-\overline{Q_{l k}}
$$

Air permeability can be calculated using Darcy’s Law for gases (Siau 1995), Equation 11:

$$
k=\frac{Q_{\text {panel }} L\left(100 \overline{\left.p_{a}\right)}\right.}{A(100 \Delta p) \frac{(100 \bar{p})+(100 \overline{p)}}{2}}
$$

The pressure differential across panel $\Delta p$ is calculated by subtracting $\bar{p}$ from $\bar{p}_{a}$, Equation 12 .

$$
\Delta p=\overline{p_{a}}-\bar{p}
$$

Substituting Equations (10) and (12) into Equation (11), the following Equation is obtained Equation 13:

$$
k=\frac{2 L\left(Q-\overline{Q l k) p_{a}}\right.}{A 100\left(\overline{p_{a}}-\bar{p}\right)\left(\overline{p_{a}}+\bar{p}\right)}
$$

Here, the lower detection limit of $Q_{\text {panel }}$ is chosen to be $\overline{Q_{l k}}+3 \sigma$.Thus, the air permeability is determined using the following Equation 14, Equation 15.

$$
\begin{array}{ll}
k=\frac{2 L\left(Q-\overline{Q_{l k}}\right) \overline{p_{a}}}{A 100\left(\overline{p_{a}}-\bar{p}\right)\left(\overline{p_{a}}+\bar{p}\right)} & (\mathrm{Q} \geq 0,000000000096) \\
k<\frac{2 L\left(\overline{Q_{l k}}-3 \sigma\right) \overline{p_{a}}}{A 100\left(\overline{p_{a}}-\bar{p}\right)\left(\overline{p_{a}}+\bar{p}\right)} \quad(\mathrm{Q} \geq 0,000000000096)
\end{array}
$$

For the analysis of the well-permeable panels (OSB, particleboard, and MDF) using a surge tank, the following Equation 16 is used: 


$$
k=\frac{2 L Q \overline{p_{a}}}{A 100\left(\overline{p_{a}}-\bar{p}\right)\left(\overline{p_{a}}+\bar{p}\right)}
$$
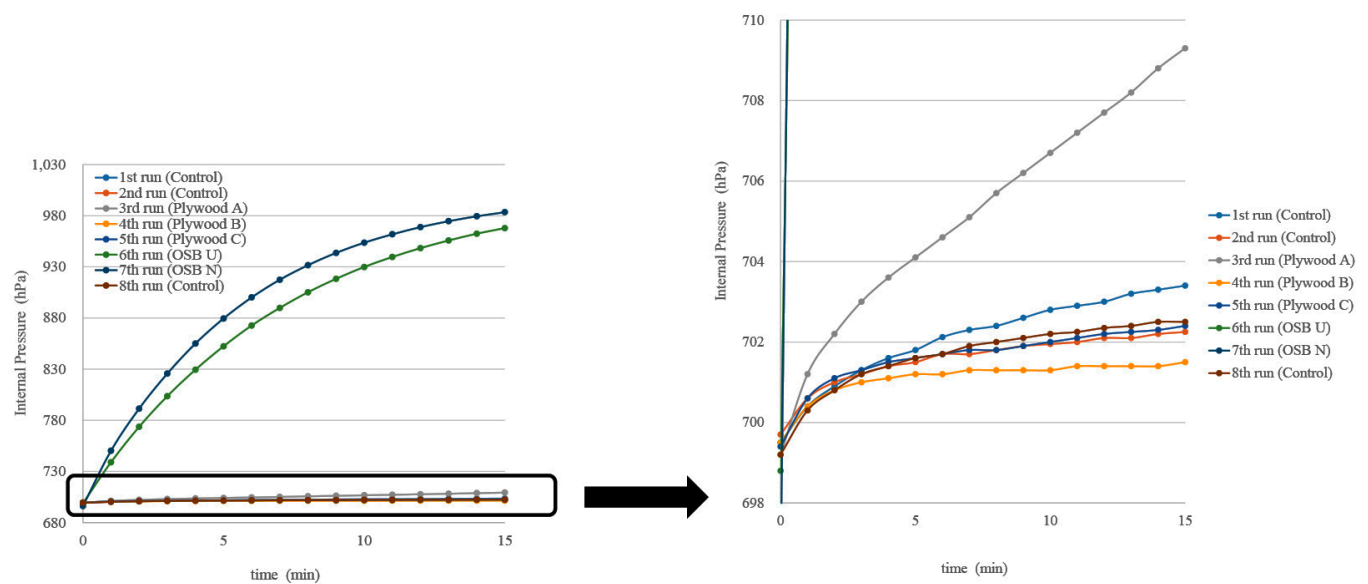

Figure 7: Relationship between time and the internal pressure in the panel specimen experiment.

Figure 8a shows the air permeability of the panel specimens except for plywood, indicating no significant difference between the results with and without a surge tank. The use of a surge tank makes the proposed method suitable for a wood-based panel of higher permeability. Moreover, there is no significant difference between the results determined with the proposed method and the conventional method (Tanaka 2014). This indicates that the method proposed in the present study can evaluate the air permeability if well permeable panels as accurate as the conventional method (Siau 1995).

Figure $8 \mathrm{~b}$ shows the air permeability of the plywood panels. No significant difference was observed in Plywood A between the results determined in the present study and in the previous study (Tanaka 2014), whereas considerable differences were shown for Plywood B and Plywood C. In a previous study (Tanaka 2014), a 6-mm inner diameter measurement tube was used, and 10-minute multiple measurements of the control specimen were conducted to determine the background flow rate due to leakage. However, variation in atmospheric pressure during measurement influences the readings of change in water level. According to the Japan Meteorological Agency (2020), the average atmospheric pressure changes every $10 \mathrm{~min}$ in a city on a day was 0,13 $\mathrm{hPa}$. Considering $1 \mathrm{mmAq}$ is equal to $0,1 \mathrm{hPa}$, atmospheric pressure variation during a 10 -minute measurement in the previous study caused an average change of $1,3 \mathrm{~mm}$ in water level. This amount of change in water level is the equivalent of $0,000000000061 \mathrm{~m}^{3} / \mathrm{s}$ volumetric change $\left(3 \times 3 \times 3,14 \times 1,3 \mathrm{~mm}^{3} / 600 \mathrm{~s}\right)$, which is much larger than the $Q_{\mathrm{lk}}$ variation determined in the present study (Equation 7). This consideration leads us to conjecture that the method proposed in the present study is less affected by the atmospheric pressure variation and thus provides a more precise evaluation for wood-based panels with very low permeability, such as plywood. 

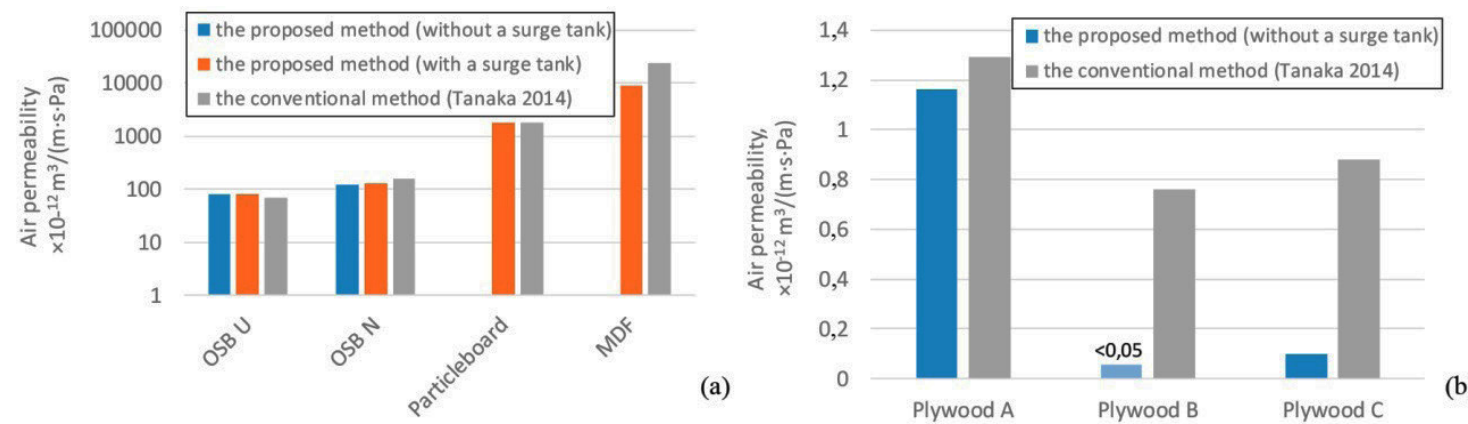

Figure 8: Air permeability of the testing panels. (a) results of OSB, particleboard and MDF (b) results of plywood.

\section{Robustness of the proposed method against variations in atmospheric pressure}

Figure 9a shows the changes in the internal pressure of the system and the atmospheric pressure during the long-term experiment of the control sample. Figure $9 \mathrm{~b}$ shows the relationship between the atmospheric pressure change rate and the internal pressure change rate. The coefficient of determination $\mathrm{R}^{2}$ was low, indicating that there is no influence of variation in atmospheric pressure on the precision of the proposed method. This robustness against atmospheric pressure change leads to precise measurement in a long-term continuous experiment for the evaluation of specimens with extremely low permeability.
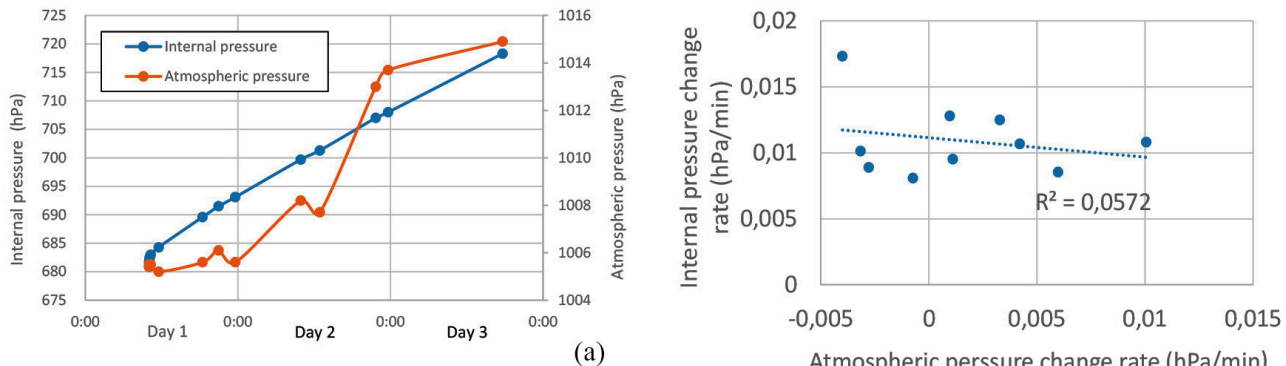

(b)

Figure 9: Relationship between internal pressure and atmospheric pressure. (a) changes in the internal and atmospheric pressures (b) relationship between atmospheric pressure change rate and the internal pressure change rate.

Overall, the proposed method is more versatile in different wood-based panels than the conventional method (Siau 1995). It is probably applicable to solid wood and non-wood materials as well.

\section{CONCLUSIONS}

In this study, a new method for determining the air permeability of wood-based panels without using water displacement was proposed. It is as valid as the conventional method for measuring air permeability in materials over a wide range of air permeability. It also provides a rigorous measurement against variation in atmospheric pressure, suggesting that the proposed method is suitable for a long-term continuous experiment for the evaluation of a specimen with even lower permeability. 


\section{REFERENCES}

Ai, W.; Duval, H.; Pierre, F.; Perré, P. 2017. A novel device to measure gaseous permeability over a wide range of pressures: characterisation of slip flow for Norway spruce, European beech and wood-based materials. Holzforschung 71: 147-162. https://doi.org/10.1515/hf-2015-0264

Comstock, G.L. 1970. Directional permeability of softwoods. Wood Fiber Sci 1(4): 283-289. https:/www.fpl.fs.fed.us/documnts/pdf1970/comst70a.pdf

Choong, E.T.; Fogg, P.J. 1968. Moisture movement in six wood species. For Prod J 18(5): 66-70.

Fujii, T.; Suzuki, Y.; Kuroda, N. 1997. Bordered pit aspiration in the wood of Cryptomeria japonica in relation to air permeability. IAWA J 18(1): 69-76. https://doi.org/10.1163/22941932-90001462

Japan Meteorological Agency. 2020. Statistics in Shizuoka City on June 30th, 2020. http://www.data.jma.go.jp/obd/stats/etrn/view/10min_s1.php?prec_no=50\&block_no=47656\&year $=2020 \&$ month $=06 \&$ day $=30 \&$ view $=p 1$

Lihra, T.; Cloutier, A.; Zhang, S.Y. 2000. Longitudinal and transverse permeability of balsam fir wet wood and normal heartwood. Wood Fiber Sci 32(2): 164-178. https://wfs.swst.org/index.php/wfs/article/view/1581

Matsumura, J.; Tsutsumi, J.; Oda, K. 1994. Relationships of bordered pit aspiration to longitudinal gas permeability in a given stem level: preliminary discussion on air-dried wood of Cryptomeria japonica and Larix leptolepis (in Japanese). Bulletin of the Kyushu University Forests 71: 35-46. https://doi.org/10.15017/10935

Perré, P. 1987. Measurements of softwoods' permeability to air: importance upon the drying model. International Communications in Heat and Mass Transfer 14: 519-529. https://doi.org/10.1016/0735-1933(87)90016-9

Perré, P. 2007. Fluid migration in wood. In: Perré, P. (ed) Fundamentals of wood drying. A.R.BO.LOR.: Nancy, France, pp. 125-156.

Petty, J.A.; Puritch, G.S. 1970. The effects of drying on the structure and permeability of the wood of Abies grandis. Wood Sci Technol 4: 140-154. https://doi.org/10.1007/BF00365299

Poonia, P.K.; Hom, S.K.; Sihag, K.; Tripathi, S. 2016. Effect of microwave treatment on longitudinal air permeability and preservative uptake characteristics of chir pine wood. Maderas-Cienc Tecnol 18(1): $125-132$. http://dx.doi.org/10.4067/S0718-221X2016005000013

Rayirath, P.; Avramidis, S. 2008. Some aspects of western hemlock air permeability. Maderas-Cienc Tecnol 10(3): 185-193. http://dx.doi.org/10.4067/S0718-221X2008000300002

Resch, H.; Echlund, B.A. 1964. Permeability of wood-exemplified by measurements on redwood. For Prod J 14(5): 199-206.

Siau, J.F. 1995. Permeability. In Wood: influence of moisture on physical properties. Siau, J.F. (ed.). Virginia Polytechnic Institute and State University, Blacksburg: NY, USA, pp. 39-58.

Taghiyari, H.R.; Avramidis, S. 2019. Specific gas permeability of normal and nanosilver-impregnated solid wood species as influenced by heat-treatment. Maderas-Cienc Tecnol 21(1): 89-96. https://doi.org/10.4067/S0718-221X2019005000108.

Tanaka, T. 2014. Determination of the air permeabilities of wood-based panels in the through-thickness direction by using rising-water volume displacement method. (in Japanese) Mokuzai Kogyo 69(12): 589-593.

Tanaka, T.; Kawai, Y.; Sadanari, M.; Shida, S.; Tsuchimoto, T. 2015. Air permeability of sugi (Cryptomeria japonica) wood in the three directions. Maderas-Cienc Tecnol 17(1): 17-28. http://dx.doi.org/10.4067/S0718-221X2015005000002. 


\section{LIST OF SYMBOLS}

A - panel area $\left(\mathrm{m}^{2}\right)$

d - the internal pressure increase during the period $t=10$ to $t=15(\mathrm{hPa})$

$\mathbf{k}$ - air permeability $\left(\mathrm{m}^{3} / \mathrm{m} \mathrm{Pa} \mathrm{s}\right)$

$\mathbf{L}$ - thickness of panel (m)

$\mathbf{n}$ - the leakage amount of air during the period of time from $t=10$ to $t=15$ (mol)

p - internal pressure (hPa)

$\bar{p}$ - average internal pressure during time $t=10$ to $t=15(\mathrm{hPa})$

$\Delta \mathrm{p}$ - pressure differential across panel (hPa)

$\mathbf{p}_{\mathrm{a}}$ - atmospheric pressure $(\mathrm{hPa})$

$\bar{p}_{a}$ - average atmospheric pressure during time $t=10$ to $t=15(\mathrm{hPa})$

Q - flow rate into the system under atmospheric pressure during the period $t=10$ to $t=15\left(\mathrm{~m}^{3} / \mathrm{s}\right)$

$\bar{Q}$ - Average leakage flow rate into the experimental system $\left(\mathrm{m}^{3} / \mathrm{s}\right)$

$\boldsymbol{Q}_{\mathrm{lk}}$ - the leakage flow rate into the system during time $t=10$ to $t=15\left(\mathrm{~m}^{3} / \mathrm{s}\right)$

$\mathbf{R}$ - gas constant $(\mathrm{J} / \mathrm{mol} \cdot \mathrm{K})$

T - temperature $(\mathrm{K})$

$\mathbf{t}$ - time (min)

$\Delta \mathbf{t}$ - time from $t=10$ to $t=15$ (min)

$\mathbf{V}$ - the volume of air flow into the system under atmospheric pressure during the period $t=10$ to $t=15\left(\mathrm{~m}^{3}\right)$

$\mathbf{V}_{\mathbf{i}}$ - internal volume of the system $\left(\mathrm{m}^{3}\right)$

$\mathbf{V}_{\mathbf{l k}}$ - the leakage volume of air under atmospheric pressure during the period $t=10$ to $t=15\left(\mathrm{~m}^{3}\right)$

$\sigma$ - standard deviation of the leakage flow rate $\left(\mathrm{m}^{3} / \mathrm{s}\right)$ 